\title{
Analysis Of 12- Level Cycloconverter To Minimize Thd (Total Harmonic Distortion) Level In 3-Phase Induction Motor
}

\author{
Mallepally Narendar Reddya, Dr. A S Rathore ${ }^{b}$ \\ a Research Scholar, Dept. of Electrical \& Electronics Engineering, \\ Sri Satya Sai University of Technology \& Medical Sciences, Sehore, Bhopal Indore Road, Madhya Pradesh, India \\ ${ }^{\mathbf{b}}$ Research Guide, Dept. of Electrical \& Electronics Engineering, \\ Sri Satya Sai University of Technology \& Medical Sciences, Sehore, Bhopal Indore Road, Madhya Pradesh, India
}

Article History: Received: 11 January 2021; Accepted: 27 February 2021; Published online: 5 April 2021

\begin{abstract}
These harmonics are higher than essential frequencies and cause Total Harmonics Distortion (THD) which increases the rms current and generates more warmth in the load. Numerous techniques are used to suppress the harmonics to limit the warmth in the load. Another procedure is utilized in this work to limit THD and the method to beat the low exhibition of a traditional PWM (pulse width tweak) control. In this work, the desired output voltage is accomplished by contrasting the desired sinusoidal waveform (adjusting signal) with a high frequency three-sided waveform (transporter signal). Industrial applications demands high force and long life expectancy motor drives. Three phase motor drives have restricted force density consequently Multiphase motor drives are better solutions for high force density and substantial loads. In this work a 12 level cycloconverter is designed to drive three Phase load. The loads used in the industries almost nonlinear loads like motors. Thusly, because of these nonlinear loads extra harmonics incited at the output of the 12 level cycloconverter drive with major frequency. The harmonics and THD got using our proposed technique is thought about using Mat lab/Simulink
\end{abstract}

Keywords: cycloconverter, harmonic, distortion, three phase, induction motor.

\section{Introduction}

The motor is used to change over an electrical type of energy into mechanical structure. As per the kind of supply, motors are classified as AC motors and DC motors. In today post, we will discuss the various types of three phase induction motors with working and applications. The induction motor especially three phase induction motors are broadly used AC motor to create mechanical power in industrial applications. Almost $80 \%$ of the motor is a three-phase induction motor among all motors used in industries. Subsequently, the induction motor is the most significant motor among any remaining types of motor. A three phase induction motor is a kind of AC induction motors which operates on three phase supply when contrasted with the single phase induction motor where single phase supply is expected to work it.

Notwithstanding bode and Nyquist diagrams, THD experiments also give information about the measured signal's direct conduct. The transformed information can be displayed in a so-called FFT-spectrum in which the response signal's extent is plotted versus the frequency. Afterwards, galvanostatic THD experiments were performed between $10 \mathrm{kHz}$ and $1 \mathrm{mHz}$. As the condition shows, the THD factor increases the bigger the harmonics are corresponding to the essential extent, i.e., the more non-linear a signal response is. They are called Galvanostatic EIS THD and Potentiostatic EIS THD. The Bode diagrams of the corresponding THD experiments. Subjective checking of Lissajous diagrams displaying the measured signal versus the applied signal are by and large the best way to assess the system's state. FFT-spectrum of a non-ideal, distorted sinusoidal signal.

The three phase supply current produces an electromagnetic field in the stator winding which leads to create the force in the rotor twisting of three phase induction motor having attractive field. Construction of Three-Phase Induction Motor The construction of an induction motor is simple and robust. It has fundamentally two parts; Stator Rotor Stator As the name suggests, the stator is a stationary piece of the motor. The stator of the induction motor consists of three fundamental parts; Stator Frame Stator Core Stator Winding Stator Frame The stator outline is the external piece of the motor. The capacity of the stator outline is to offer help to the stator core and stator winding. It provides mechanical strength to the inward parts of the motor. The edge has fins on the external surface for heat dissipation and cooling of the motor. The edge is casted for small machines and it is created for a huge machine. As indicated by the applications, the casing is comprised of bite the dust cast or created steel, aluminum/aluminum alloys, or stainless steel. Stator Core The capacity of the stator core is to convey the rotating attractive transition which produces hysteresis and vortex current loss. To limit these losses, the core is overlaid by high-grade steel stampings thickness of 0.3 to $0.6 \mathrm{~mm}$. These stampings are insulated from one another by varnish. All stampings stamp together in the shape of the stator core and fixed it with the stator outline. An internal layer of the stator core has various slots. Stator winding the stator winding is put inside the stator slots accessible inside the stator core. Three-phase winding is set as a stator winding. What's more, three-phase supply is given to the stator winding. The quantity of poles of a motor depends on the interior association of the stator winding and it will choose the speed of the motor. In the event that the quantity of poles is more prominent, the speed will less and if the quantity of poles is lesser than the speed will high. 


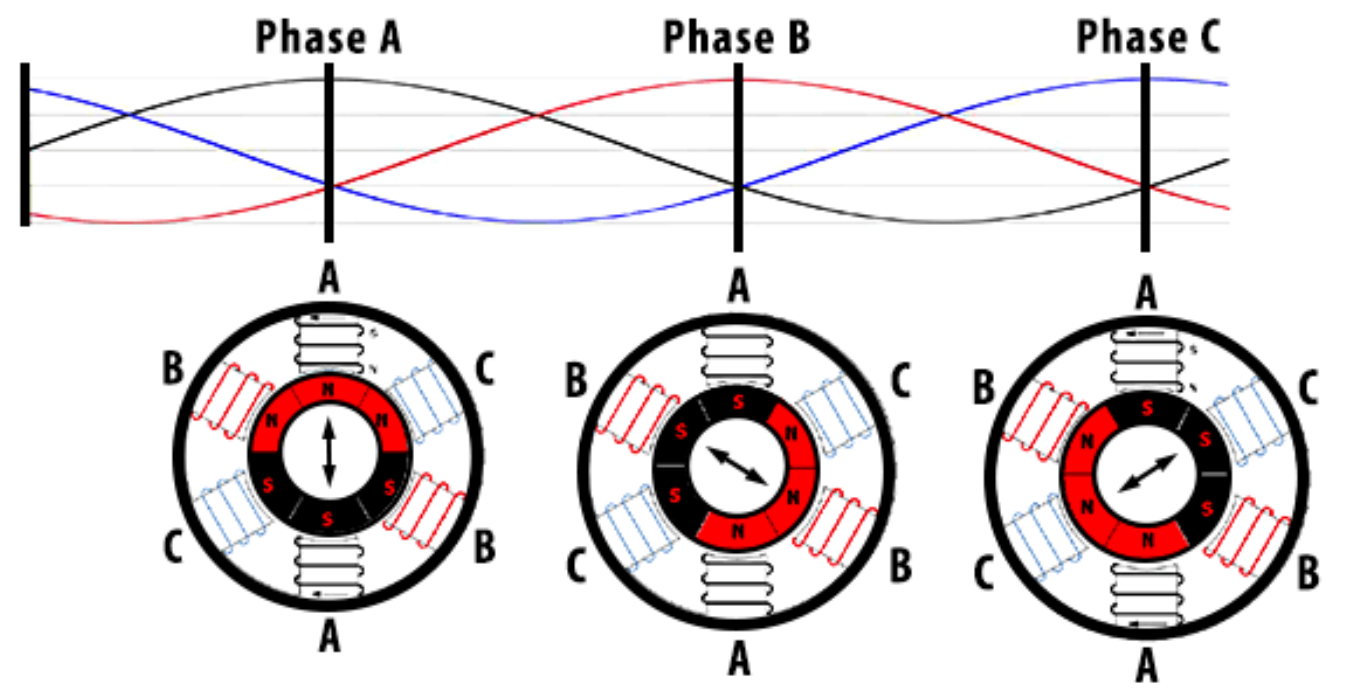

Figure 1 Three Phase Induction Motor

The measured signal $\mathrm{t}$ gives a sinusoidal response with the same frequency, however amplitude I 0 might be extraordinary, and phase point f might be shifted. Gamry Instruments' software displays these curves during EIS and THD experiments for every frequency, except they furnish no unmistakable boundary with which to work later. The peaks are called harmonics and represent the non-linear conduct of a signal. Test the results of measuring a system by using diverse AC amplitudes to create straight and non-linear informational indexes are shown in this section. Nonetheless, a system can be assumed to be direct by applying a small-enough AC amplitude. The semi-circle of the non-linear measurement information extends farther, as does the diffusion-related part at exceptionally low frequencies. The poles are always in pairs. Consequently, the total number of poles always a considerably number. The connection between synchronous speed and number poles is as shown in the underneath condition $S=120 \mathrm{f} /$ whereof $=$ Supply Frequency $\mathrm{P}=$ Total Number of Poles N s = Synchronous Speed As the finish of twisting associated with the terminal box. Subsequently, there are six terminals (two of each phase) in the terminal box. As per the application and sort of starting methods of motors, the stator winding is associated in star or delta and it is finished by the association of terminals in the terminal box. Rotor As the name suggests, the rotor is a turning part of the motor. As per the sort of rotor, the induction motor is classified as; Squirrel Cage Induction Motor Phase (Wound Rotor) Induction motor/Slip-ring Induction Motor the construction of the stator is same in the two types of induction motors.

We will discuss the types of rotors used in 3-phase induction motors in the accompanying section of types of three phase induction motors. Types of Three Phase Induction Motors Three phase motors are classified basically in two categories based on the rotor winding (Armature curl winding) for example squirrel enclosure and slip ring (wound rotor motor).Squirrel Cage Induction Motor Slip-ring or Wound Rotor Induction Motor Related Post: Brushless DC Motor (BLDC) - Construction, Working Principle and Applications Squirrel Cage Induction Motor The shape of this rotor is resembling the shape of the confine of a squirrel. Hence, this motor is known as a squirrel confine induction motor. The construction of this sort of rotor is simple and rough. So, almost $80 \%$ of the induction motor is a squirrel confine induction motor. The rotor consists of a barrel shaped covered core and has slots on the external fringe.

The slots are not equal however it is skewed at some point. It helps to forestall attractive locking between the stator and rotor teeth. It results in smooth activity and reduces the murmuring noise. The THD factor is determined for every frequency analogous to the impedance Z. THD E -curves of a coin cell using diverse AC amplitudes. Linearity can't be ensured if the AC amplitude is set inappropriately. Prior to every measurement, the battery was charged to $3.6 \mathrm{~V}$ and afterward potentiostatically held at this potential for $4 \mathrm{~h}$. For this, a CR2032 lithium-ion battery with an ostensible limit of $40 \mathrm{mAh}$ was used. A completely straight signal as shown in Figure 3 gives a factor of $0 \%$. For simplicity, just two graphs using $4 \mathrm{~mA}$ (orange) and $40 \mathrm{~mA}$ (blue) AC amplitudes. Total Harmonic Distortion: Theory and Practice*Please note THD is just accessible in software version 7 or higher this application note discusses Total Harmonic Distortion (THD), what sharescharacteristics with Electrochemical Impedance Spectroscopy (EIS). It increases the length of the rotor conductor because of this the rotor resistance is increased. The squirrel confine rotor consists of rotor bars instead of the rotor winding. The rotor bars are comprised of aluminum, brass, or copper. Rotor bars are forever shorted by end rings. So, it makes a total close way in the rotor circuit. The rotor bars are welded or propped with the end rings to offer mechanical help. The rotor bars are short-circuited. In this manner, it is unrealistic to add outer resistance to the rotor circuit. In this kind of rotor, the slip rings and brushes are not used. Consequently, the construction of this kind of motor is simpler and more robust. Slip-ring or Wound Rotor Induction Motor Slip-ring induction motors are also 
known as wound rotor motor. The rotor consists of a covered tube shaped core with slots on the external outskirts. The rotor winding is put inside the slots. In this sort of rotor, the rotor winding is injured in such a manner that, the quantity of poles of rotor winding is the same as the quantity of poles of the stator winding. The rotor winding can be associated as a star or delta. End terminals of rotor windings are associated with the sliprings. So, this motor is known as a slip-ring induction motor.

\section{LITERATURE REVIEW}

BandlaPavanBabu (2020): In an electrical system, power quality (PQ) is getting significant to a wide range of consumers. With the increase of power interest from end users, keeping up the quality of power inside the limitations is a significant issue. This paper describes power quality issues like voltage sag, voltage variations, voltage fluctuations, singular harmonics, between harmonics and power frequency variations in a lattice associated system with a three-phase induction motor associated as a load. This system is tested in as per International Electro specialized Commission (IEC) Std. 61000-4-11/4-13/4-14/4-28 which are permitted to the load through a regenerative network simulator. Test procedures of the system hardware and the nitty gritty analysis of the checked and measured results are also described in this paper.

Ankush Raina (2016): Harmonic Distortion in power system increasing regularly because of increase in the use of nonlinear loads such as wave rectifiers and other solid state controlled devices. Some of the sources of harmonic currents in household appliances incorporate the electronic components we use like computers, printers, telecom gear, miniature ovens, UPS systems and other electronic loads will increase the progression of harmonic currents. In industries use of variable frequency drives and other power electronic gears such as rectifiers, inverters improve the progression of harmonic current. This paper present demonstrating and simulation of impact of harmonic on three phase induction motor. Since induction motors are the principle working electrical machine in our industrial system. The impact of harmonic are studied on parameters like rotor speed, electromagnetic force, rotor current and stator force. The results are contrasted and the system having less or zero harmonics. The entire system is utilized by using MATLAB/SIMULINK software.

JineshDerawala (2017): The requirement for use of cycloconverter (AC to AC converters) is in controlling a.c motors at low speed drive especially in high power application. When designing such sort of converters, output will have the issue of power quality. Henceforth to improve power quality and lessen the total harmonic distortion to specific standards pulse numbers should be increased. The undertaking includes the MATLAB/SIMULINK model of cycloconverter on various pulses. Pulse number will increase to decrease total harmonic distortion. Comparison will be made in the wake of finishing the simulation process. The control strategy of supplying the terminating pulses is based on the cosine wave crossing technique. The MATLAB/SIMULINK model for the control circuits to play out the system of this strategy will be constructed. The cycloconverter will work satisfactory having either number of pulses. By increasing number of pulses of cycloconverter will redress the output waveforms of cycloconverter and will invalidate the harmonic impact, which result in progress in output power factor. Great concurrence with them, which indicates that the system is dependable.

\section{PROPOSED METHODOLOGY}

Design of Cycloconverter using Thyristors This paper is designed to control the speed of a single phase induction motor in three steps by using a Cycloconverter procedure by Thyristors. For the application where variable speed requires, this motor is not used. Speed control of this motor is troublesome. The induction motor has a high starting inrush current. Otherwise, the squirrel confine induction motor is more liked over slip-ring induction motor. Working Principle of Three-Phase Induction Motor The stator winding is covered at $120^{\circ}$ (electrically) to one another. Yet, it never catches it. Also, is toward the pivoting attractive field instigated by the stator. Here, the rotor current is delivered because of inductance. It does not need outside DC supply for excitation like a synchronous motor. The induction motor is a self-starting motor.

By this game plan, the brushes and outer resistance is taken out from the rotor circuit. This reduces the rotor copper loss as well as erosion in brushes. The rotor circuit cut the stator attractive field and an EMF initiated in the rotor bar or rotor winding. The rotor circuit is a close way. Henceforth, the motor can't run. The induction motor is a broadly used motor in industries. At the point when a three-phase supply is given to the stator winding, the pivoting attractive field (RMF) actuated in the stator circuit. The speed of the turning attractive field is known as synchronous speed (N S).According to Faraday's law, EMF actuated in the conductor because of the pace of progress of motion $(\mathrm{d} \varphi / \mathrm{dt})$. Henceforth, the speed of the rotor is slightly less than the speed of synchronous speed.The synchronous speed depends on the quantity of poles and supply frequency.

Also, it draws more current. Consequently, it needs just one supply of source. What's more, it is useful for controlling the speed of the motor and improving the starting force of the three-phase induction motor. An electrical outline of slip-ring three-phase induction motor with outside resistance is shown in the underneath figure. The outside resistance is used distinctly for the starting purpose. So, because of this EMF current will 
course through the rotor circuit. Presently, we realize that the current-conveying conductor induces the attractive field. The rotor tries to get the stator transition and starts pivoting. The heading of revolution is given by the Lenz's law. Hence, this motor is known as the induction motor. The speed of the rotor is less than the speed of synchronous speed. Because it has a bigger number of advantages than disadvantages. Advantages and Disadvantages of Induction Motors Advantages The advantages of induction motor are listed as underneath, the construction of a motor is simple and robust. The working of an induction motor is extremely simple. It can work in any ecological condition. The effectiveness of the motor is extremely high. The upkeep of an induction motor is less contrasted with different motors. It is a single energized motor. So, it does not need any additional auxiliaries for the starting purpose for typical activity. The cost of this motor is less contrasted with different motors.

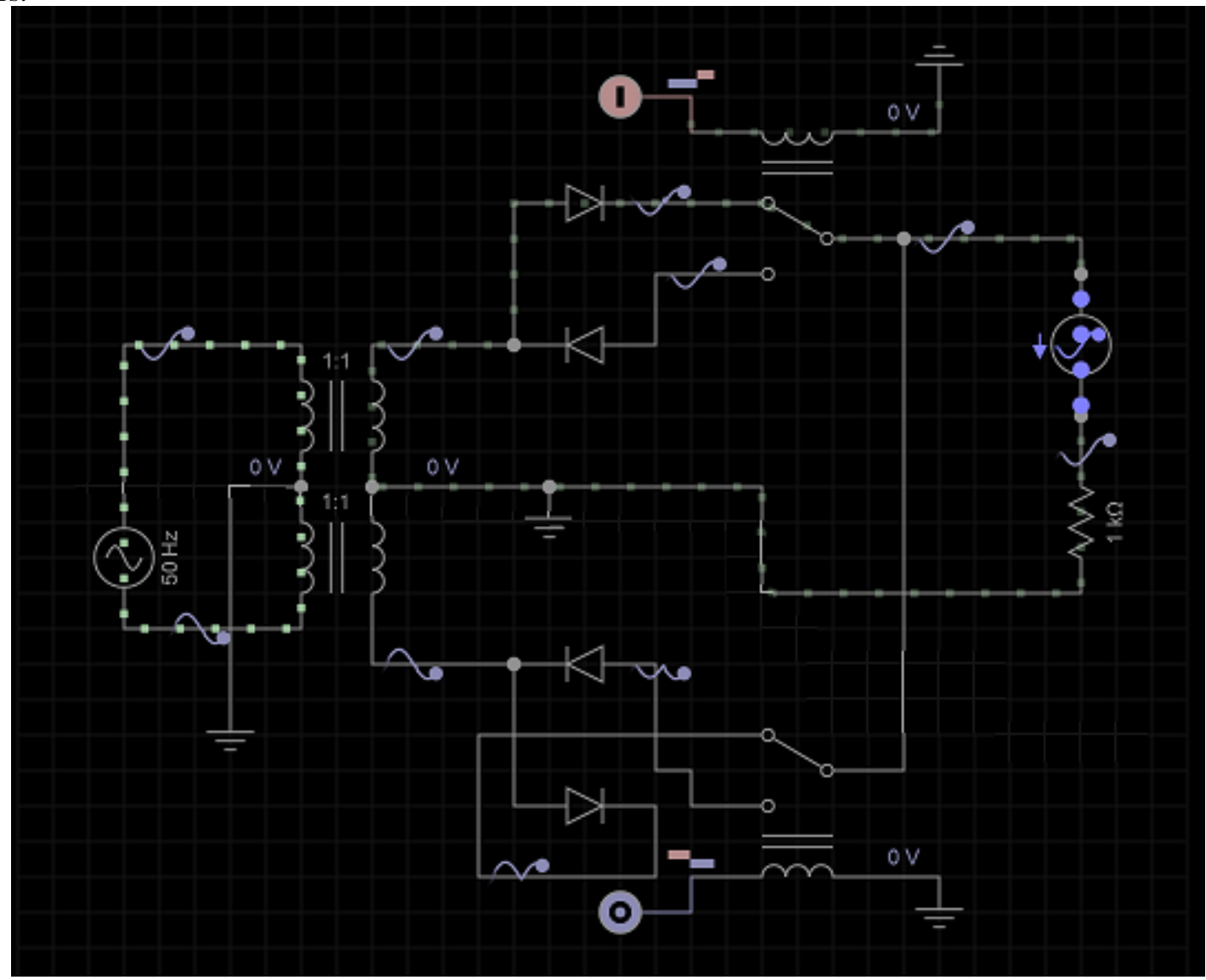

Figure 2 Cycloconverter Circuit

The life expectancy of this motor is extremely high. Armature response is less. Related Post: Direct Online Starter DOL Starter Wiring Diagram for Motors. The disadvantages of the motor are listed as beneath; during light load condition, the power factor is extremely less. So, the rotor current induces a second attractive field. The overall movement between the stator transition and rotor motion, the rotor starts to turn to diminish the cause of relative movement. The outer resistance can easily associate with the rotor circuit through the slip-ring and brushes. Hence, no EMF incited in the rotor circuit and rotor current is zero. The contrast between the real speed of the rotor and synchronous speed is known as slip. At the point when the real speed of the rotor is equivalent to the synchronous speed, the slip is zero. So, the copper loss is more which diminish the effectiveness during light load condition. The starting force of this motor (squirrel confine induction motor) is not less. The induction motor is a constant speed motor. So, the outside resistance is associated with the rotor circuit during the starting condition. At the point when motor running close to the speed of the genuine speed, the slip-rings are short-circuited by the metal collar. The rotor construction is somewhat muddled contrasted with the squirrel confine motor because of the presence of brushes and slip-rings. The support of this motor is more. For the induction motor, this condition won't ever occur. Because when the slip is zero, the two speeds are equivalent and there is no relative movement. This causes a decrease in voltage at the hour of starting. Use of 3Phase Induction Motors the induction motor is mostly used in industrial applications. So, this motor possibly used when variable speed control and high starting force are required. In the event that it is remains associated during the running condition, it will increase the rotor copper loss. High rotor resistance is useful for the starting condition. The rotor tries to get the pivoting attractive field of the stator. 


\section{EXPERIMENT RESULT}

On the off chance that one converter is working the other one is disabled, no current passes through it. Threephase to Single-phase This Cycloconverter operates in four quadrants that are $(+\mathrm{V},+\mathrm{I})$ and $(-\mathrm{V},-\mathrm{I})$ being the correction modes and $(+\mathrm{V},-\mathrm{I})$ and $(-\mathrm{V},+\mathrm{I})$ being the inversion modes. Three-phase to Three-phase This Cycloconverter is significantly used in AC machine systems that are working on three phase induction and synchronous machines. Cycloconverter is a frequency converter starting with one level then onto the next that can change AC power from one frequency to AC power at another frequency. Here, the Op-amp is used as a comparator. The $5 \mathrm{~V} \mathrm{DC}$ is given to an expected divider of $47 \mathrm{k}$ and $10 \mathrm{~K}$ which gives an output of about $1.06 \mathrm{~V}$ and that is associated with transforming input pin no $2.10 \mathrm{~ms}$ ) we need to get zero signals. This is accomplished by using pulsating DC after the scaffold rectifier prior to being sifted. For that purpose, we are using an impeding diode D3 between pulsating DC and the channel capacitor so that we can get pulsating DC for use. The pulsating DC is given to likely divider of $6.8 \mathrm{k}$ and $6.8 \mathrm{~K}$ to convey an output about $5 \mathrm{~V}$ pulsating from $12 \mathrm{~V}$ pulsating which is associated with the non-upsetting input of comparator pin 3. Eight Opto - Isolators MOC3021 are used for driving 8 SCR's U2 to U9.4 SCR's (silicon controlled rectifiers) used in full scaffold is in antiparallel with another set of 4 SCR's as shown in the chart. The undertaking uses zero voltage reference as described above at pin no. It is imperative to keep the non-directing Thyristor exhibit off consistently, otherwise, the mains could be short circuited by means of the two Thyristor arrays, resulting in waveform distortion and possible gadget disappointment from the shorting current.

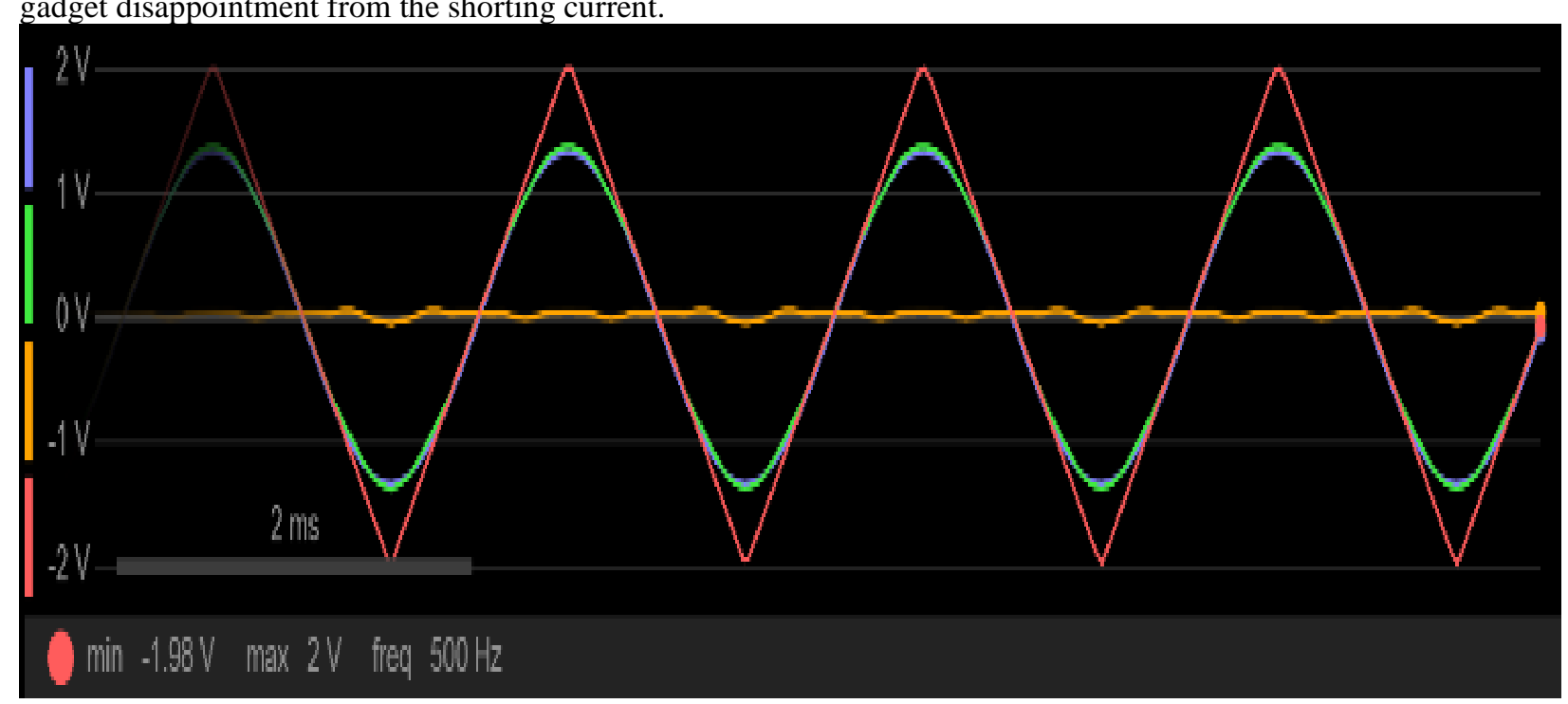

Figure 3 Harmonic Distortion

A significant control issue of the cyclo-converter is the manner by which to swap between banks in the shortest possible opportunity to stay away from distortion while ensuring the two banks don't lead at the same time. A typical expansion to the power circuit that removes the necessity to keep one bank off is to put a middle tapped inductor called a coursing current inductor between the outputs of the two banks. The two banks would now be able to lead together without shorting the mains. Similarly, for F/3 the conduction takes place for 30ms in the $1 \mathrm{st}$ extension and next $30 \mathrm{~ms}$ from the following scaffold, such that a total time-frame of 1 cycle comes to $60 \mathrm{~ms}$ which thus in F/3 while switch - 2 is worked. The Fundamental frequency of $50 \mathrm{~Hz}$ is accessible by setting off on a couple from the 1 st extension for $1 \mathrm{st} 10 \mathrm{~ms}$ and for the following $10 \mathrm{~ms}$ from the following scaffold while both the switches are kept in "OFF" condition. The reverse current streaming in the gates of the SCR's are Opto isolator output. Applications of Cycloconverter Applications incorporate Controlling the speed of AC machines like it is essentially used in electric foothold, AC motors having variable speed and induction warming. Synchronous Motors cap can change AC power from one frequency to AC power at another frequency. Here, an $\mathrm{AC}-\mathrm{AC}$ conversion process is finished with a frequency change. One resistance of $1 \mathrm{~K}$ is used from output pin 1 to the input pin 2 for criticism. As we probably are aware the rule of a comparator is that when the nonrearranging terminal is more noteworthy than the altering terminal, at that point the output is rationale high (supply voltage). 


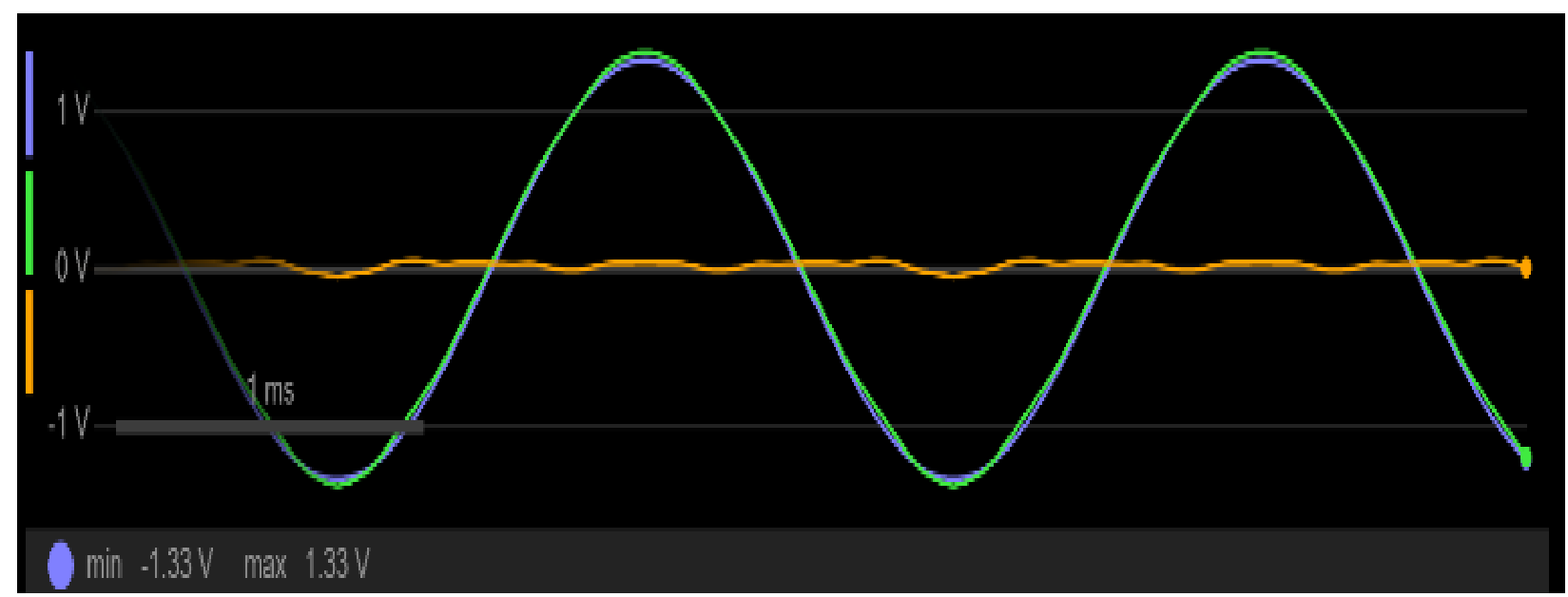

Figure 4 Reduced Harmonic Distortion

This ZVR is then used as input pulses to the Microcontroller. Working Procedure of Cycloconverter the circuit connections are shown in the above outline. Setting off pulses so produced by the MC according to the program composed provides input condition to the Opto isolator that drives the respective SCR. Power transfer inside a Cycloconverter occurs in two directions. There are two types of CycloconvertersStep up Cycloconverter: These types use ordinary compensation and give an output at higher frequencies than that of the input. Step down Cycloconverter: This sort uses constrained substitution and results in an output with a frequency lower than that of the input. The cyclo-converters are additionally classified into three categories as discussed beneath. Zero Voltage Cross Detection Zero voltage cross recognition means the supply voltage waveform that passes through zero voltage for each $10 \mathrm{msec}$ of a $20 \mathrm{msec}$ cycle. Also, the need to use replacement circuits is not necessary because it utilizes characteristic recompense. 13 of the Microcontroller. Consequently it is also alluded as frequency transformer. At the point when the positive current flows in the load, the output voltage is constrained by phase control of the two positive exhibit Thyristors whereas, the negative cluster Thyristors are kept off and the other way around when negative current flows in the load. The ideal output waveforms for a sinusoidal load current and various load phase angles is shown in Figure beneath. Thus the pulsating DC on pin no 3 is contrasted and the fixed DC $1.06 \mathrm{~V}$ at pin no 2 .

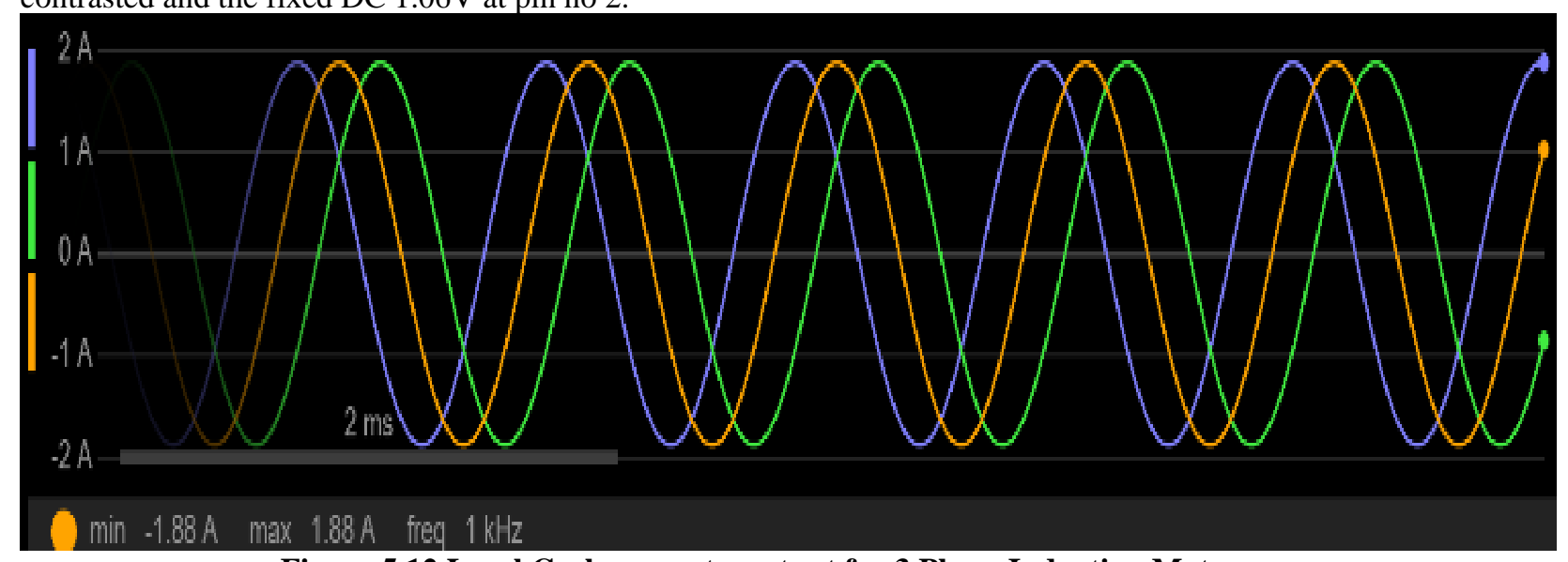

Figure 512 Level Cycloconverteroutput for 3 Phase Induction Motor

The $\mathrm{o} / \mathrm{p}$ of this comparator is taken care of to the rearranging terminal of another comparator. The Microcontroller or DSP or microprocessor is used in charge circuits. A cyclo-converter can accomplish frequency conversion in one stage and ensures that voltage and the frequencies are controllable. Also, the coursing current in the inductor keeps the two banks working constantly, resulting in improved output waveforms.

\section{CONCLUSION}

A 12 level cycloconverter drive is constructed using simulink/Matlab to study the harmonics and THD at the output of the inverter and thought about the results got using proposed strategy for 12 level cycloconverter. From the resultant figure we can presume that our proposed philosophy works well to decrease Total Harmonic Distortion. It is observed that the rate in THD at the output of the cycloconverter is discovered to be less than PWM Inverter Drive. The figure 3 represent that there are more harmonic distortion present in the induction motor. The figure 4 represent the diminished harmonic distortion in the three phase induction motor. The figure 
5 represent that the 12 level cycloconverter output for three phase induction motor which is sans distortion. In this way, it is inferred that the decrease of harmonics is favor to diminish the warmth created because of motor loads used in the industry. The same work is reached out to study the temperature analysis of three phase Induction motor.

\section{REFERENCES}

1. JineshDerawala 2017 "Reduction of Total Harmonic Distortion using MultipulseCycloconverter" eISSN: 2395 -0056

2. Ankush Raina 2016 "Effect of Harmonics on Performance Characteristics of Three Phase Induction Motor" ISSN: 2454-1532

3. BandlaPavanBabu 2020 "Analysis of power quality in a grid system connected with a three phase induction motor" DOI: https://doi.org/10.1515/ijeeps-2020-0054

4. Santos, V.S.; Eras, J.J.C.; Gutierrez, A.S.; Ulloa, M.J.C. Assessment of the energy efficiency estimation methods on induction motors considering real-time monitoring. Measurement 2019, 136, 237-247.

5. Debruyne, C.; Lieven, V.; Jan, D. Harmonic effects on induction and line start permanent magnet machines. EEMODS 2013. 4. Singh, G. A research survey of induction motor operation with nonsinusoidal supply wave forms. Electr. Power Syst. Res. 2005, 75, 200-213.

6. Rata, M.; Rata, G. Study solution of induction motor dynamic braking. In Proceedings of the 2016 International Conference on Development and Application Systems (DAS), Suceava, Romania, 19-21 May 2016; pp. 33-37.

7. Vengatesan, K., Kumar, A., Chavan, V., Wani, S., Singhal, A., \& Sayyad, S. (2019). Simple Task Implementation of Swarm Robotics in Underwater. In International Conference on Emerging Current Trends in Computing and Expert Technology (pp. 1138-1145).

8. Bednarz, S.; Dybkowski, M. Estimation of the Induction Motor Stator and Rotor Resistance Using Active and Reactive Power Based Model Reference Adaptive System Estimator. Appl. Sci. 2019, 9, 5145.

9. Salomon, C.P.; Santana, W.; Lambert-Torres, G.; Da Silva, L.B.; Bonaldi, E.L.; De Oliveira, L.; Da Silva, L.E.B. Comparison among Methods for Induction Motor Low-Intrusive Efficiency Evaluation Including a New AGT Approach with a Modified Stator Resistance. Energies 2018, 11, 691.

10. Kumar, A., Kumar, P., Srivastava, A., Kumar, V., Vengatesan, K., \& Singhal, A. (2020). Comparative Analysis of Data Mining Techniques to Predict Heart Disease for Diabetic Patients. In International Conference on Advances in Computing and Data Sciences (pp. 507-518)

11. Wang, K.; Huai, R.; Yu, Z.; Zhang, X.; Li, F.; Zhang, L. Comparison Study of Induction Motor Models Considering Iron Loss for Electric Drives. Energies 2019, 12, 503.

12. Debruyne, C.; Desmet, J.; Derammelaere, S.; Vandevelde, L. Derating factors for direct online induction machines when supplied with voltage harmonics: A critical view. In Proceedings of the 2011 IEEE International Electric Machines \& Drives Conference (IEMDC), Niagara Falls, ON, Canada, 15-18 May 2011; pp. 1048-1052. 